The Open Dentistry Journal
Bentham open
Content list available at: www.benthamopen.com/TODENTJ/
DOI: $10.2174 / 1874210601711010001$

RESEARCH ARTICLE

\title{
Prevalence of the Short Face Pattern in Individuals of Bauru-Brazil
}

\author{
Douglas Rezende Bastos, Ana Cláudia de Castro Ferreira Conti , Leopoldino Capelozza Filho,
} Renata Rodrigues de Almeida-Pedrin and Maurício de Almeida Cardoso

Department of Orthodontics, Sagrado Coração University, Bauru, Brazil

Received: July 18, 2016

Revised: December 02, 2016

Accepted: December 22, 2016

\section{Abstract:}

Aim:

This study aimed at assessing the prevalence and severity of short face pattern in ethnically different individuals.

\section{Material and Methods:}

The sample comprised 4,409 Brazilians (2,192 females and 2,217 males), with a mean age of 13 years, enrolled in secondary schools in the municipality of Bauru. The sample inclusion criteria involved subjects with vertically impaired facial relationship based on excessive lip compression, when standing at natural head position, with the lips at rest. Once short face syndrome had been identified, the individuals were classified into three severity subtypes: mild, moderate, and severe. The sample was then stratified by ethnic background as White (Caucasoid), Black (African descent), Brown (mixed Caucasian-African descent), Yellow (Asian descent), and Brazilian Indian (Native Brazilian descent), using the Brazilian Institute of Geography and Statistics classification. The chi-square test at the $5 \%$ significance level was used to compare frequency ratios of individuals with vertically impaired facial relationships and across different ethnicities, according to severity.

\section{Results:}

The prevalence of short face pattern was $3.15 \%$, as $1.11 \%, 1.99 \%$, and $0.02 \%$ considered mild, moderate and severe subtypes, respectively. The severe subtype was rare $(0.02 \%)$ and found only in one White individual. The White group had the highest relative frequency (45.53\%) of the moderate subtype, followed by Brown individuals (43.40\%). In the mild subtype, Yellow (68.08\%) and White (62.21\%) individuals showed similar and higher relative frequency values.

\section{Conclusion:}

The prevalence of short face pattern was $3.15 \%$, and White individuals had the highest prevalence.

Keywords: Epidemiology, Orthodontics, Malocclusion, Frequency of short face pattern, Excessive lip compression.

\section{INTRODUCTION}

The short face pattern is determined by facial and skeletal changes that characterize the individual who presents vertical deficiency of the lower third of the face and compressive lip sealing. They present nose breathing and swallow with the mouth closed with no tongue interposition, resulting in intra- and perioral functions which potentially predispose these individuals to normality. Dental and occlusal features include deep overbite, a tendency toward vertical displacement of the maxillary incisors, lingual flexion of the mandibular incisors, increased curve of Spee, incisor crowding, no exposure of the anterior maxillary teeth at rest, and limited tooth exposure on smiling [1 - 12]. Short-faced patients may also present with various types of malocclusion, such as Class II, Division 2; Class II, Division 1: Class I occlusion with symptoms of Class II, Division 2; and even Class III [11 - 13].

\footnotetext{
* Address correspondence to this author at the Department of Orthodontics, Sagrado Coração University, Rua Irmã Arminda, 10-50 - Jardim, Zip Code: 17011-170 Bauru/SP Brazil; Tel: +5514997957795; E-mails: accfonti@uol.com.br, accfconti@hotmail.com
} 
The facial structure of short-faced individuals is strong, and the skeleton has a marked radiographic appearance. This is especially true for the mandible, which exhibits a broad ramus, a wide and short symphysis and an expressive chin $[9,14]$. The load on the jaws is increased due to hyperfunction of the masticatory muscles. This load can lead to increased sutural growth and bone apposition, which, in turn, result in increased transverse growth of the maxilla and wider bony bases for the dental arches [2, 5, 6, 9, 15]. Even the type and distribution of the masseter muscle fibers differ depending on the vertical dysplasia. Moreover, in the short face pattern, white fast-twitch fibers (type II) predominate, rather than red (type I) slow-twitch fibers [16].

The condyle and mandibular ramus usually undergo anterior growth while the gonial angle remains closed [6, 8, 9]. Decreased lower anterior face height (LAFH) may be caused by vertical growth of the condyle, which exceeds the sum of the vertical growth that occurs in the facial sutures and in the alveolar process, resulting in forward and upward mandibular rotation, associated with the influence exerted by the development of a respiratory and masticatory pattern. Increases in anterior surface height are greatly influenced by the growth of the cervical spine and the resulting differential growth of the muscles, fascia, and other soft tissue located between the skull, mandible, hyoid bone, and shoulder girdle. Individuals with this vertical deformity develop an improper growth pattern, perpetuating characteristics which are quite abnormal in the lower third of the face $[1-5,7,8,15,17]$.

Vertical malocclusions such as the short face may be due to a combination of etiological factors, such as variability in growth intensity, mandibular soft tissue and muscle function, and dentoalveolar development. Although it is clear that mandibular growth is the most important of these factors, all must be taken into account, including soft-tissue aspects and cephalometric parameters [8].

Some cephalometric studies investigated the association between facial morphology and malocclusion and revealed that hypodivergent individuals with a closed gonial angle develop deep overbite and are predominantly affected by Angle Class II, Division 2 malocclusions [13]. Another investigation examined facial vertical dimension in an African ethnic group (Shona) and reported a reduced LAFH compared to White Americans and African-Americans [18].

Features related to facial morphology have been discussed in individuals with cleft lip [19], however the literature lacks epidemiological studies focusing solely on facial pattern. In epidemiological surveys, division of data by ethnic group is essential, as many studies have reported racial differences in facial features [20]. The Brazilian population features a high degree of miscegenation, and has been classified as the most heterogeneous population in the world [21]. The state of São Paulo belongs to the Southeast region of the country, which may be representative of Brazil in terms of ethnicity distribution. Thus, this survey sought to assess the distribution of vertical deficiency (stratified into three levels of severity) and determine the prevalence of short face pattern in an ethnically diverse sample.

Based on the gap of the literature regarding epidemiological survey that considers uniquely the facial pattern in short face individuals, this study was conducted. This is of great importance for clinicians, especially with regard to the determination of treatment prognosis and its inherent limitation $[2,11,16,22]$.

\section{MATERIAL AND METHODS}

This study was approved by the Research Ethics Committee of Sagrado Coração University (212/11). The sample comprised 4,409 Brazilians enrolled in public and private middle schools (grades 5-8) in the municipality of Bauru: 2,192 females (49.72\%) and 2,217 males (50.28\%). The individuals were aged 10 years to 16 years and 11 months, with a mean age of 13 years $(\mathrm{SD}=1$ year and 3 months) for the total sample, 12 years and 11 months $(\mathrm{SD}=1 \mathrm{year}$ and 3 months) for females, and 13 years ( $\mathrm{SD}=1$ year and 3 months) for males.

By design, this study was limited to morphological facial analysis. Regarding ethnicity, individuals were classified as White (Caucasian), Black (Afro-Brazilian), Brown (Mulatto), Yellow (Asian descent), or Native Brazilian (indigenous Brazilian descent), in accordance with the criteria established by the Brazilian Institute of Geography and Statistics (IBGE). The ethnic distribution of the residents of the city of Bauru, Brazil, and of the overall sample is shown in Table 1. As well as skin color (assessed on the inside of the forearm), hair color and texture, eye color, and the shape of the lips, nose, and mouth were also taken into account for classification, as per Parra et al. [21].

Table 1. Ethnic distribution of residents and evaluated sample in the city of Bauru-SP (Source: Ministry of Planning, budget and management. Brazilian Institute of Geography and Statistics).

\begin{tabular}{|c|c|c|c|}
\hline Ethnicity & Total & \% & Evaluated \\
\hline White & 237,925 & 75.67 & 2,948 \\
\hline
\end{tabular}




\begin{tabular}{|c|c|c|c|c|}
\hline Ethnicity & Total & $\%$ & Evaluated & $\%$ \\
\hline Brown & 55,504 & 17.65 & 1,041 & 20.73 \\
\hline Black & 15,281 & 4.86 & 279 & 5.56 \\
\hline Yellow & 5,096 & 1.62 & 141 & 2.81 \\
\hline Native & 625 & 0.20 & 0 & 0 \\
\hline Total & 314,431 & $100 \%$ & 4,409 & $100 \%$ \\
\hline
\end{tabular}

Clinically observable syndromes and/or a history of surgery or fractures in the facial or skull region were criteria for exclusion. However, a history of previous or ongoing orthopedic and/or orthodontic treatment was not an exclusion criterion, because neither of these treatment modalities is able to significantly alter facial proportions and relationships [11]. All individuals were evaluated under natural light, in standing natural head position, with the lips at rest and without the aid of any special equipment. Examination was performed by one of the authors, who is experienced in orthodontics and was properly calibrated for facial morphology evaluation [20].

The criterion for the identification of patients with vertically deficient facial relationships is morphological and based on lip competence, i.e., excessive lip compression at rest [16]. Once identified, individuals with vertically impaired facial relationships were classified into three subtypes according to severity: mild, moderate, or severe. The method for this classification has been thoroughly described elsewhere and has proven to be reliable in a previous study [19] that demonstrated intra- and inter-examiner agreement.
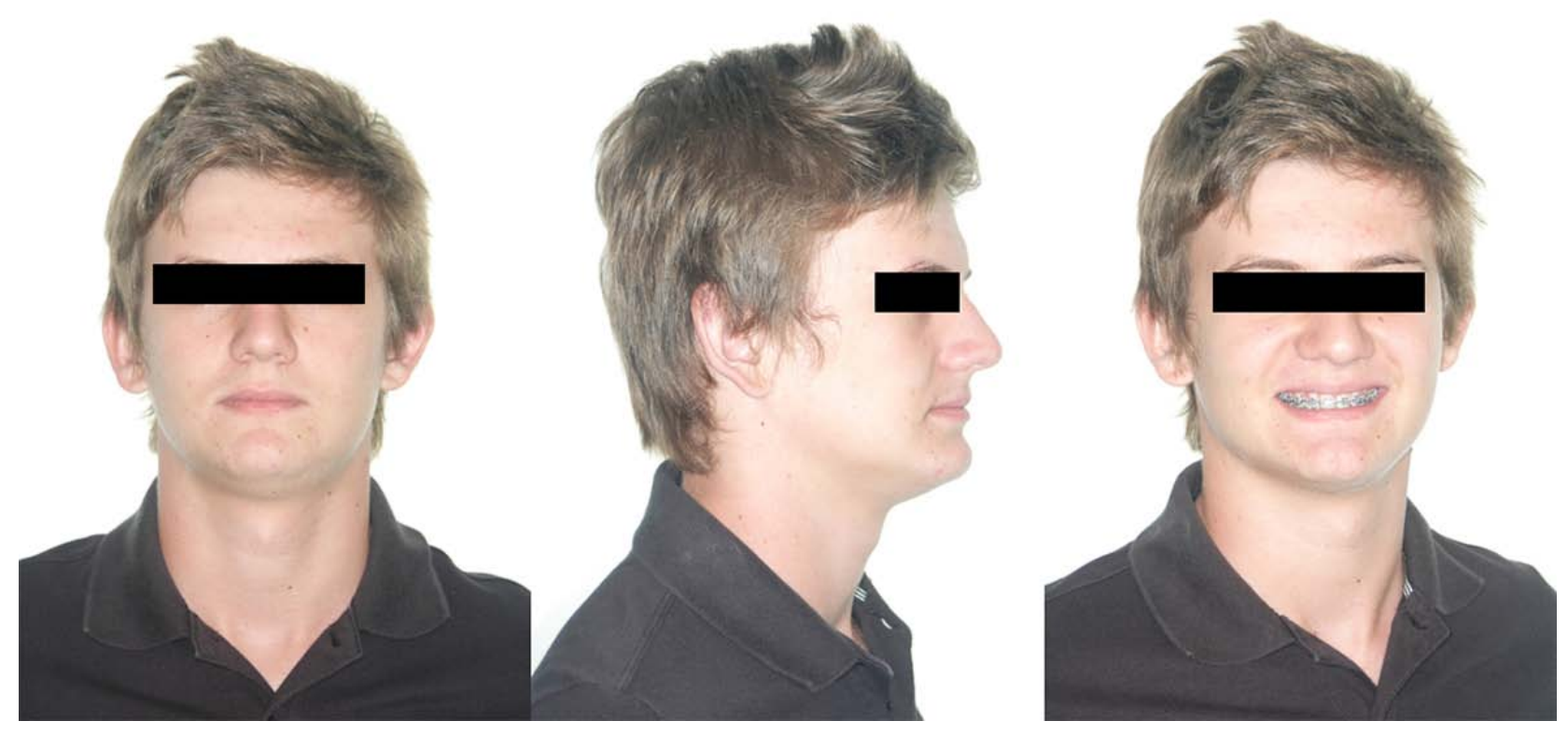

Fig. (1). Front and lateral view facial photographs representative of an individual with the mild subtype of short face pattern.

Briefly, classification criteria were as follows. For the mild subtype, mandatory presence of lip compression and/or presence of a moderate disproportion between the middle and lower thirds, even with the postural component; in summary, these individuals could be considered as borderline Class I, brachyfacial (Fig. 1). For the moderate subtype, the classification criterion was the presence of a true disproportion between the middle and lower thirds, in addition to the features described for the mild subtype; this combination undoubtedly characterizes a short face pattern (Fig. 2). For classification in the severe subtype, individuals had to present with severe disproportion between the middle and lower facial thirds, associated with features described in the previous subtype and combined with more typical signs of the short face pattern, severe enough to cause unattractiveness. In these individuals, prognosis is poor for conservative treatment, and orthognathic surgery is indicated for normalization of facial relationships (Fig. 3).

For statistical processing, all results were analyzed in the Statistica 5.1 software environment (Stat Soft Inc., Tulsa, OK, USA). The chi-square $\left(\chi^{2}\right)$ test was used at a significance level of $5 \%(p<0.05)$ to compare the frequency ratios of individuals with vertically impaired facial relationships in the overall sample and among different ethnicities, stratified by the three levels of severity. 

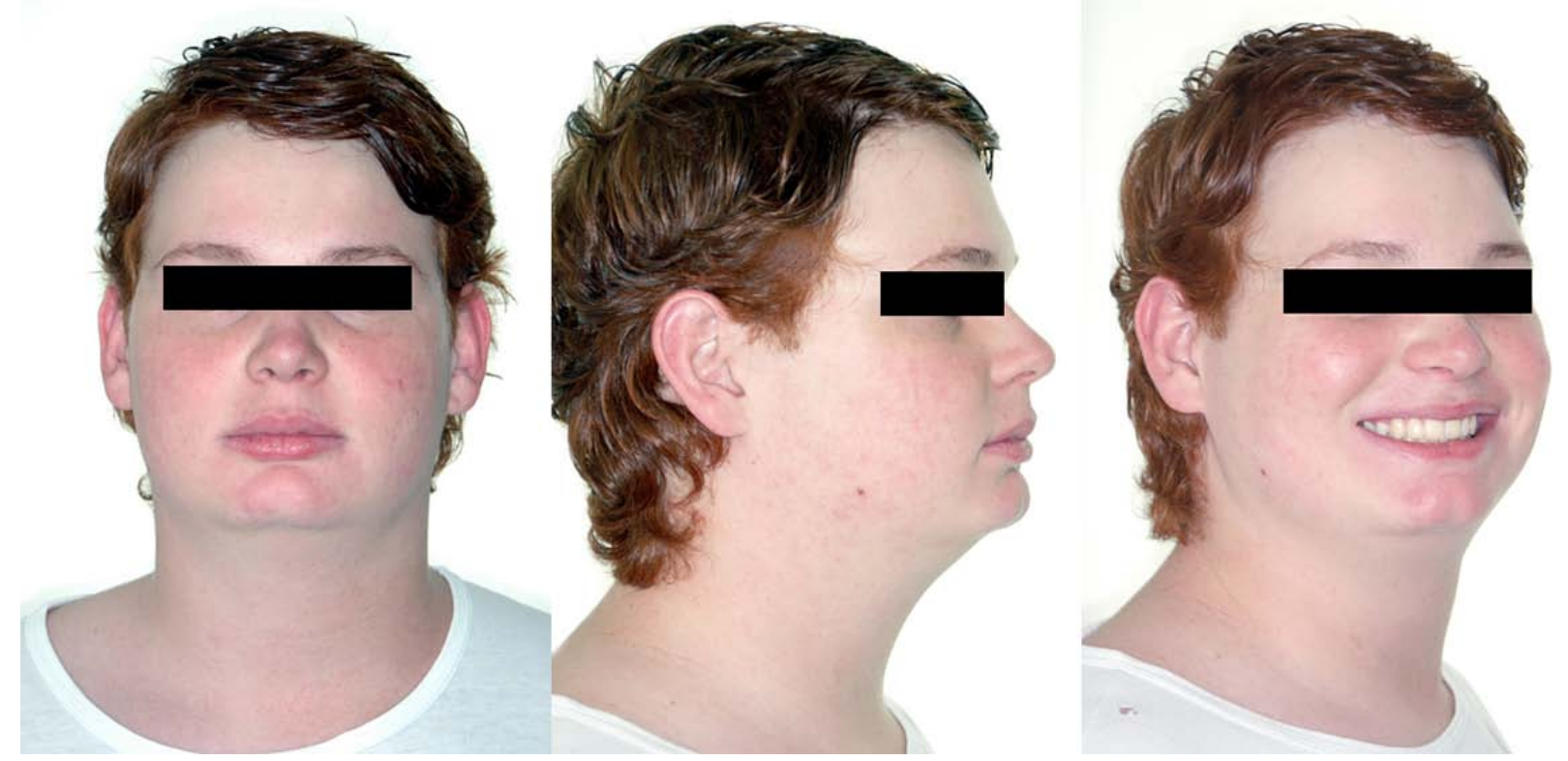

Fig. (2). Front and lateral view facial photographs representative of an individual with the moderate subtype of short face pattern.
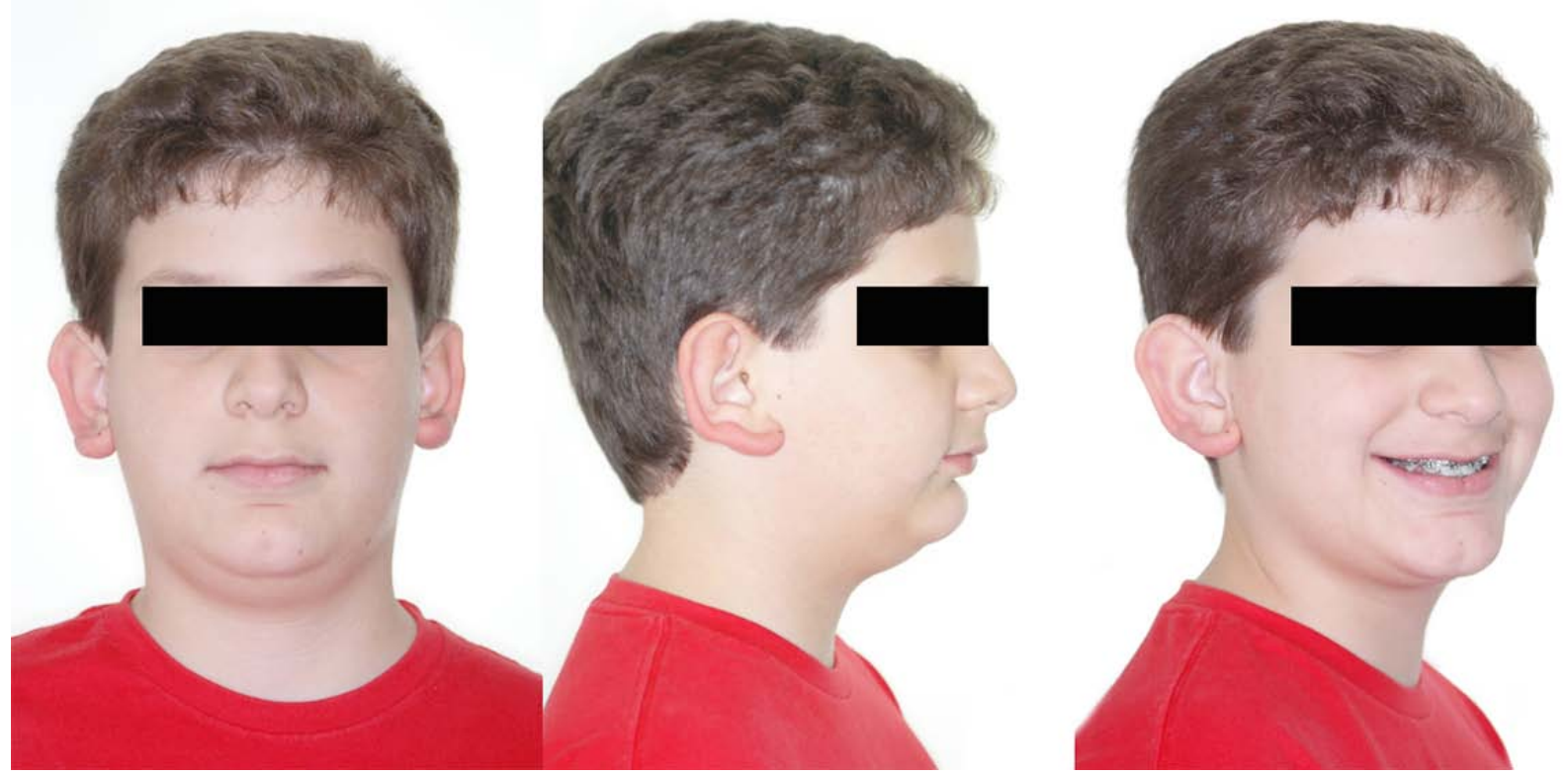

Fig. (3). Front and lateral view facial photographs representative of an individual with the severe subtype of short face pattern.

\section{RESULTS}

Evaluation of intra- and inter-examiner error in a previous study [19] revealed moderate agreement, thus demonstrating the accuracy of the present methodology. Overall, $3.15 \%$ of the pooled sample exhibited vertical deficiency, 34.94\% exhibited vertical excess (long face pattern), and $61.91 \%$ met criteria for other patterns (i.e., pattern I, II, or III). Considering that the short face pattern consists of mild, moderate, and severe subtypes, of the 139 individuals with a short face pattern in this sample, $35.97 \%$ belonged to the mild subtype (corresponding to $1.11 \%$ of the overall sample), $63.30 \%$ to the moderate subtype (corresponding to $1.99 \%$ of the overall sample), and $0.71 \%$ to the severe subtype (corresponding to $0.02 \%$ of the overall sample) (Tables $\mathbf{2}$ and $\mathbf{3}$ ). 
Table 2. Distribution of the prevalence of individuals with vertical deficiency and other patterns, according to severity, for each ethnic group.

\begin{tabular}{|l|c|c|c|c|c|c|c|c|c|c|}
\hline \multirow{2}{*}{ Pattern/Race } & \multicolumn{2}{|c|}{ Mild } & \multicolumn{2}{|c|}{ Moderate } & \multicolumn{2}{c|}{ Severe } & \multicolumn{2}{c|}{ Other patterns } & \multicolumn{2}{c|}{ Total } \\
\cline { 2 - 13 } & $\mathbf{n}$ & $\mathbf{\%}$ & $\mathbf{n}$ & $\mathbf{\%}$ & $\mathbf{n}$ & $\mathbf{\%}$ & $\mathbf{n}$ & $\mathbf{\%}$ & $\mathbf{n}$ & $\mathbf{\%}$ \\
\hline White & 41 & 0.92 & 79 & 1.79 & 1 & 0.02 & 2,827 & 64.11 & 2,948 & 66.84 \\
\hline Brown & 5 & 0.11 & 9 & 0.20 & 0 & 0.00 & 1,027 & 23.29 & 1,041 & 23.61 \\
\hline Yellow & 1 & 0.02 & 0 & 0.00 & 0 & 0.00 & 140 & 3.17 & 141 & 3.19 \\
\hline Black & 3 & 0.06 & 0 & 0.00 & 0 & 0.00 & 276 & 6.25 & 279 & 6.32 \\
\hline Total & $\mathbf{5 0}$ & $\mathbf{1 . 1 1}$ & $\mathbf{8 8}$ & $\mathbf{1 . 9 9}$ & $\mathbf{1}$ & $\mathbf{0 . 0 2}$ & $\mathbf{4 . 2 7 0}$ & $\mathbf{9 6 . 8 2}$ & $\mathbf{4 . 4 0 9}$ & $\mathbf{1 0 0 . 0 0}$ \\
\hline
\end{tabular}

Table 3. Comparison of relative frequencies among individuals with vertical deficiency, according to severity, for each ethnic group.

\begin{tabular}{|l|c|c|c|c|c|c|c|c|}
\hline \multirow{2}{*}{ Pattern/Race } & \multicolumn{2}{|c|}{ Mild } & \multicolumn{2}{|c|}{ Moderate } & \multicolumn{2}{c|}{ Severe } & \multicolumn{2}{c|}{ Total } \\
\cline { 2 - 10 } & $\mathbf{N}$ & $\mathbf{\%}$ & $\mathbf{N}$ & $\mathbf{\%}$ & $\mathbf{n}$ & $\mathbf{\%}$ & $\mathbf{N}$ & $\mathbf{\%}$ \\
\hline White & 41 & 33.88 & 79 & 65.29 & 1 & 0.83 & 121 & 100.00 \\
\hline Brown & 5 & 35.71 & 9 & 64.29 & 0 & 0.00 & 14 & 100.00 \\
\hline Yellow & 1 & 100.00 & 0 & 0.00 & 0 & 0.00 & 1 & 100.00 \\
\hline Black & 3 & 100.00 & 0 & 0.00 & 0 & 0.00 & 3 & 100.00 \\
\hline Total & $\mathbf{5 0}$ & $\mathbf{3 5 . 9 7}$ & $\mathbf{8 8}$ & $\mathbf{6 3 . 3 0}$ & $\mathbf{1}$ & $\mathbf{0 . 7 1}$ & $\mathbf{1 3 9}$ & $\mathbf{1 0 0 . 0 0}$ \\
\hline
\end{tabular}

$\chi^{2}=7.46 ; \mathrm{p}=0.2800 ;$ NS.

When the relative frequencies were analyzed (Table 3), the moderate subtype was the most frequent severity in White (65.29\%) and Brown (64.29\%) individuals. One subject in the Yellow subset (100\%) and three in the Black subset $(100 \%)$ had the mild subtype. Once again, White $(33.88 \%)$ and Brown $(35.71 \%)$ individuals showed similar relative frequency values of the mild subtype, with the moderate subtype predominating in these ethnic groups. The severe subtype was rare in all races; only one individual, in the White subgroup, exhibited this condition. The percentages of individuals with vertical deficiency according to severity for each gender were presented in Table 4.

Table 4. Percentages of individuals with vertical deficiency according to severity for each gender.

\begin{tabular}{|l|c|c|c|c|c|}
\hline & Others & MILD & MODERATE & SEVERE & Total \\
\hline Female & 2098 & 33 & 60 & 1 & 2192 \\
\hline$\%$ & $95.71 \%$ & $1.51 \%$ & $2.74 \%$ & $0.05 \%$ & 0 \\
\hline Male & 2172 & 17 & 28 & $0.00 \%$ & 2217 \\
\hline$\%$ & $97.97 \%$ & $0.77 \%$ & $1.26 \%$ & $\mathbf{1}$ & $\mathbf{4 4 0 9}$ \\
\hline Total & $\mathbf{4 2 7 0}$ & $\mathbf{5 0}$ & $\mathbf{8 8}$ & & \\
\hline
\end{tabular}

$\chi^{2}=18.897 ; \mathrm{p}=0.000 ;$ sig.

\section{DISCUSSION}

Epidemiological data pertaining to the prevalence of a given condition play an important role in the evaluation of treatment in a given population to support the development of patient care programs. For this reason, the assignment of specific criteria to diagnose or quantify a disease or condition is paramount. This study aimed at investigating the prevalence of vertical deficiency in facial relationships, and, specifically, the prevalence of the short face pattern in a sample of primary school students from the municipality of Bauru. Considering the prevalence found in this study $(3.15 \%)$ regarding a sample of 4,409 subjects, for a confidence interval of $95 \%$, the estimated margin of error for this sample is $0.5 \%$.

Subjective facial analysis parameters, which base classification on the presence or absence of specific conditions, are not less validated or less reproducible. This method can be considered as an easier alternative for use in surveys, with good reproducibility as long as examiners are calibrated [19, 20].

Regarding our sample, its ethnic distribution can be considered representative of the municipality of Bauru, except for the Brazilian Indian population, which is concentrated in the rural area and was not covered by the present survey (Table 1). However, the ethnic distribution found in this survey cannot be considered representative of Brazil. Thus, it may represent the distribution of the short face pattern in different races in Bauru, but not of a racial group in Brazil as a whole. 
Corroborating the results of this study, Capelozza Filho et al. [19] found 0\% prevalence of the short face pattern when assessing cleft patients. Their results are particularly important because the authors assessed samples recruited from the same geographic area as our study. Another cephalometric research [13] found that about $40 \%$ of individuals had hypodivergent growth. However, a direct comparison with the results of this study would be unfeasible, given the disparate methodology employed, which considered only facial morphology analysis for diagnosis.

The low prevalence of vertical deficiency found in the present survey $(3.15 \%)$ could be explained by the age of the individuals (11 to 16 years), since the short face pattern worsens with aging [11]. When adults are evaluated, the prevalence of short face syndrome might increase.

In terms of prevalence of the different degrees of vertical deficiency severity, individuals with a moderate level of severity predominated. Eighty-eight of the 139 participants had moderate severity, representing 1.99\% of the sample; this differed markedly from the prevalence of vertical excess (34.94\%) reported by Cardoso et al. [20]. The prevalence of the short face pattern with mild severity was $1.11 \%$, while severe cases accounted for $0.02 \%$ of the sample.

Regarding the frequency distribution of the short face pattern by ethnicity, White subjects had the highest prevalence $(3.87 \%)$, followed by Brown (1.50\%), Black (1.20\%), and Yellow (1.03\%) participants. The predominance of the short face pattern in the different racial groups, stratified by severity, is shown in Table 3. Most cases were of moderate severity in the White and Brown subset of the sample. Yellow and black individuals showed mild severity. The only individuals characterized as severe short face were white. Contrary to the results of this study, research by Cardoso et al. [20] found a higher prevalence of vertical excess in Black patients, followed by Brown, White, and Yellow individuals. Considering this as a reflection of the direction of growth, these conflicting results appear only logical, as vertical excess predominates in Black subjects, while horizontal excess predominates in Whites.

When the prevalence of individuals with different levels of short face severity was compared between genders, the incidence was higher in females (4.29\%) than males $(2.03 \%)$. This outcome also contrasts with the results of the study by Cardoso et al. [20], where the highest prevalence of the long face pattern was observed in males. As noted for the racial discrepancy above, this apparent conflict between results seems to represent the logic of facial growth, with vertical excess predominating in men and horizontal excess predominating in women.

Facial growth patterns are the primary etiological factor behind malocclusions. The short face pattern is no exception to this rule, as the malocclusions found in subjects with this pattern are primarily the result of growth in locations where there is no dental compensation. As the orthodontic treatment is limited to dentoalveolar areas, the aim of approach in short face individuals is an attempt to camouflage the vertical facial deformity, and this information is clinically relevant to orthodontists.

Although the sample was significant, the main limitation of this study regards that this findings are not representative of the whole Brazilian population specially because the age range comprised only teenagers.

\section{CONCLUSION}

Short face pattern accounted for 3.15\% of individuals of Bauru, Brazil. White individuals had the highest prevalence than other background ethinics.

\section{CONFLICT OF INTEREST}

The authors confirm that this article content has no conflict of interest.

\section{ACKNOWLEDGEMENTS}

"Similar study with 'long face pattern' has been previously published in J. Appl. Oral Sci. vol. 21 no. 2 Bauru Mar./Apr. 2013".

\section{REFERENCES}

[1] Beckmann SH, Kuitert RB, Prahl-Andersen B, Segner D, The RP, Tuinzing DB. Alveolar and skeletal dimensions associated with lower face height. Am J Orthod Dentofacial Orthop 1998; 113(5): 498-506.

[http://dx.doi.org/10.1016/S0889-5406(98)70260-4] [PMID: 9598607]

[2] Björk A, Skieller V. Normal and abnormal growth of the mandible. A synthesis of longitudinal cephalometric implant studies over a period of 25 years. Eur J Orthod 1983; 5(1): 1-46.

[http://dx.doi.org/10.1093/ejo/5.1.1] [PMID: 6572593] 
[3] Blanchette ME, Nanda RS, Currier GF, Ghosh J, Nanda SK. A longitudinal cephalometric study of the soft tissue profile of short- and longface syndromes from 7 to 17 years. Am J Orthod Dentofacial Orthop 1996; 109(2): 116-31. [http://dx.doi.org/10.1016/S0889-5406(96)70172-5] [PMID: 8638557]

[4] Houston WJ. Mandibular growth rotationstheir mechanisms and importance. Eur J Orthod 1988; 10(4): 369-73. [http://dx.doi.org/10.1093/ejo/10.4.369] [PMID: 3061834]

[5] Karlsen AT. Craniofacial characteristics in children with Angle Class II div. 2 malocclusion combined with extreme deep bite. Angle Orthod 1994; 64(2): 123-30. [PMID: 8010520]

[6] McDowell EH, Baker IM. The skeletodental adaptations in deep bite correction. Am J Orthod Dentofacial Orthop 1991; 100(4): 370-5. [http://dx.doi.org/10.1016/0889-5406(91)70076-9] [PMID: 1927988]

[7] Nanda SK. Patterns of vertical growth in the face. Am J Orthod Dentofacial Orthop 1988; 93(2): 103-16. [http://dx.doi.org/10.1016/0889-5406(88)90287-9] [PMID: 3422525]

[8] Nielsen IL. Vertical malocclusions: etiology, development, diagnosis and some aspects of treatment. Angle Orthod 1991; 61(4): 247-60. [PMID: 1763835]

[9] Opdebeeck H, Bell WH. The short face syndrome. Am J Orthod 1978; 73(5): 499-511. [http://dx.doi.org/10.1016/0002-9416(78)90240-3] [PMID: 277066]

[10] Pollard D, Akyalcin S, Wiltshire WA, Rody WJ Jr. Relapse of orthodontically corrected deepbites in accordance with growth pattern. Am J Orthod Dentofacial Orthop 2012; 141(4): 477-83.

[http://dx.doi.org/10.1016/j.ajodo.2011.11.013] [PMID: 22464530]

[11] Turley PK. Orthodontic management of the short face patient. Semin Orthod 1996; 2(2): 138-53. [http://dx.doi.org/10.1016/S1073-8746(96)80049-1] [PMID: 9161276]

[12] Wessberg GA, Fish LC, Epker BN. The short face patient: surgical-orthodontic treatment options. J Clin Orthod 1982; 16(10): 668-85. [PMID: 6960003]

[13] Siriwat PP, Jarabak JR. Malocclusion and facial morphology is there a relationship? An epidemiologic study. Angle Orthod 1985; 55(2): $127-38$.

[PMID: 3874569]

[14] Swasty D, Lee J, Huang JC, et al. Cross-sectional human mandibular morphology as assessed in vivo by cone-beam computed tomography in patients with different vertical facial dimensions. Am J Orthod Dentofacial Orthop 2011; 139(4)(Suppl.): e377-89. [http://dx.doi.org/10.1016/j.ajodo.2009.10.039] [PMID: 21435546]

[15] Kiliaridis S. Masticatory muscle influence on craniofacial growth. Acta Odontol Scand 1995; 53(3): 196-202. [http://dx.doi.org/10.3109/00016359509005972] [PMID: 7572097]

[16] Rowlerson A, Raoul G, Daniel Y, et al. Fiber-type differences in masseter muscle associated with different facial morphologies. Am J Orthod Dentofacial Orthop 2005; 127(1): 37-46.

[http://dx.doi.org/10.1016/j.ajodo.2004.03.025] [PMID: 15643413]

[17] Jago JD. The epidemiology of dental occlusion; a critical appraisal. J Public Health Dent 1974; 34(2): 80-93 [http://dx.doi.org/10.1111/j.1752-7325.1974.tb00682.x] [PMID: 4275506]

[18] Dandajena TC, Chung KW, Nanda RS. Assessment of anterior face height in a native African sample. Am J Orthod Dentofacial Orthop 2006; 130(2): 196-201.

[http://dx.doi.org/10.1016/j.ajodo.2004.11.039] [PMID: 16905064]

[19] Capelozza Filho L, Cardoso MA, An TL, Lauris JR. Proposal for classification of individuals with long face pattern malocclusions according to severity. Rev Dent Press Ortodon Ortop Facial 2007; 12: 124-58

[20] Cardoso MdeA, Castro RC, Li A T, Normando D, Garib DG, Capelozza F L. Prevalence of long face pattern in Brazilian individuals of different ethnic backgrounds. J Appl Oral Sci 2013; 21(2): 150-6.

[http://dx.doi.org/10.1590/1678-7757201302270] [PMID: 23739865]

[21] Parra FC, Amado RC, Lambertucci JR, Rocha J, Antunes CM, Pena SD. Color and genomic ancestry in Brazilians. Proc Natl Acad Sci USA 2003; 100(1): 177-82. [http://dx.doi.org/10.1073/pnas.0126614100] [PMID: 12509516]

[22] Van Der Linden FP. O desenvolvimento das faces longas e curtas e as limitações do tratamento. Dental Press J Orthod 1999; 4(6): 6-11.

(C) Bastos et al.; Licensee Bentham Open

This is an open access article licensed under the terms of the Creative Commons Attribution-Non-Commercial 4.0 International Public License (CC BY-NC 4.0) (https://creativecommons.org/licenses/by-nc/4.0/legalcode), which permits unrestricted, non-commercial use, distribution and reproduction in any medium, provided the work is properly cited. 